\title{
Photosynthetic genes in Rhodobacter capsulatus can be regulated by oxygen during dark respiratory growth with dimethylsulphoxide
}

\author{
Francesca Leach, ${ }^{1}{ }^{*}$ Gregory A. Armstrong ${ }^{1,2} \ddagger$ and John E. Hearst ${ }^{1,2}$ \\ ${ }^{1}$ Laboratory of Chemical Biodynamics, Lawrence Berkeley Laboratory and ${ }^{2}$ Department of Chemistry, \\ University of California, Berkeley, CA 94720, USA
}

(Received 22 November 1990; revised 15 January 1991; accepted 18 March 1991)

\begin{abstract}
In the purple non-sulphur bacterium Rhodobacter capsulatus, genes encoding structural polypeptides of the lightharvesting (LH) and reaction center (RC) complexes incorporated into an intracytoplasmic photosynthetic membrane are induced upon lowering the oxygen tension in the media of aerobically growing cultures. When cultures are grown microaerophilically in the dark, an intracytoplasmic photosynthetic membrane develops gratuitously if a terminal oxidant, such as dimethylsulphoxide (DMSO) is present in the medium. The purpose of the present study was to determine whether in these conditions, photosynthetic genes are completely derepressed or whether they are still inducible in response to a lowering of oxygen tension. Oxygen induction of mRNA for the puf and puc operons was compared in dark aerobic cultures $\left(20 \% \mathrm{O}_{2}\right)$ shifted to low oxygen conditions $\left(3 \% \mathrm{O}_{2}\right)$ allowing growth microaerophilically with or without DMSO as an accessory terminal oxidant. The extent of the induction was similar in both growth conditions, 6 to 12-fold for puf $A$ mRNA and at least 400-fold for pucB $\mathrm{mRNA}$ which encode the light-harvesting I (LHI $\alpha$ ) and light-harvesting II (LHII $\beta$ ) polypeptides, respectively. The puf and puc operons were also induced by low oxygen tension in a mutant strain blocked in an early step of bacteriochlorophyll (BChl) synthesis, suggesting that the presence of $\mathrm{BChl} \mathrm{may} \mathrm{not} \mathrm{be} \mathrm{a} \mathrm{prerequisite} \mathrm{for} \mathrm{the} \mathrm{normal}$ oxygen regulation of the genes encoding the structural polypeptides of the photosynthetic apparatus.
\end{abstract}

\section{Introduction}

Rhodobacter capsulatus is a metabolically versatile purple non-sulphur bacterium, capable of photosynthetic or chemoheterotrophic growth according to environmental conditions. It grows photosynthetically in an illuminated environment only when oxygen tension drops below $3 \%$ (Oelze \& Drews, 1972). Furthermore, in the dark, $R$. capsulatus is capable of anaerobic growth on nonfermentable sources of carbon when the medium is supplemented by either dimethylsulphoxide (DMSO) or trimethylamine- $N$-oxide (TMAO) (Yen \& Marrs, 1977; Cox et al., 1980; Madigan et al., 1980; Schultz \& Weaver,

$\dagger$ Present address: Division of Endocrinology, Beth Israel Hospital, Boston, MA 02215, USA.

$\ddagger$ Present address: Max-Planck-Institute für Züchtungsforschung, Abteilung Biochemie, D-5000 Köln 30, Germany.

\footnotetext{
Abbreviations: BChl, bacteriochlorophyll; LH, Light-harvesting complex; PS, photosynthetic; RC, reaction-center; RCV medium, DLmalate as the carbon source, ammonium sulphate as the nitrogen source, phosphate buffer, thiamine hydrochloride, and mineral salts; $\mathrm{RCV}^{+}$medium, RCV supplemented with $50 \mathrm{~mm}-\mathrm{DMSO}, 0.6 \%$ glucose and $0.5 \%$ pyruvate.
}

1982; McEwan et al., 1985) or with nitrous oxide (McEwan et al., 1984). These alternative terminal oxidants stimulate the growth of non-photosynthetic cultures and allow the gratuitous formation of an intracytoplasmic photosynthetic membrane (Yen \& Marrs, 1977). Thus it is possible to propagate nonphotosynthetic mutants in conditions in which they can express components of the photosynthetic apparatus, but where photosynthetic growth is not required. The pattern of photosynthetic gene expression during microaerophilic respiratory growth with an alternative terminal oxidant has not been previously studied. The observation that an intracytoplasmic membrane developes during dark anaerobic growth (Yen \& Marrs, 1977) implies that genes for the photosynthetic polypeptide components of the integral membrane BChl-protein complexes are expressed to some extent. We wished to determine whether bacterial cultures maintained oxygen regulation of photosynthetic gene expression in the presence of an alternative terminal oxidant. In the present paper, we have compared the growth properties of cultures of $R$. capsulatus shifted from $20 \%$ to $3 \%$ oxygen tension both in the presence and in the absence of DMSO as an accessory terminal oxidant. 


\section{Methods}

Bacterial strains, media, and growth conditions. $R$. capsulatus rifampicin-resistant strain SB1003 (Marrs, 1981) and its bchD::Tn5.7 derivative KZR8E12 (Zsebo \& Hearst, 1984) were used. Strains were grown on malate-minimal RCV medium (Weaver et al., 1975) in $250 \mathrm{ml}$ side-arm flasks at $30^{\circ} \mathrm{C}$ or in RCV supplemented with $50 \mathrm{~mm}$-DMSO, $0.6 \%$ glucose and $0.5 \%$ pyruvate $\left(\mathrm{RCV}^{+}\right)$. Neither glucose nor pyruvate supports fermentative growth of $R$. capsulatus, but they greatly enhance dark anaerobic growth when DMSO is added to RCV medium (Yen \& Marrs, 1977). Overnight dark inocula were sparged with $\mathrm{N}_{2} / \mathrm{O}_{2} / \mathrm{CO}_{2}$ $(78: 20: 2$, by vol). When cultures reached early exponential growth, the sparging gas mixture was changed to low oxygen conditions of either $95: 3: 2$ or $98: 0: 2$. The gas flow rates were approximately $250 \mathrm{~cm}^{3}$ $\mathrm{min}^{-1}$ for each culture. Gas flow rate and composition were controlled using a Matheson Gas Products Multiple Dyna-blender, model 8219. Growth rates were monitored using a Bausch and Lomb Spectronic 21 spectrophotometer.

RNA isolation and hybridization. Total RNA was extracted as described by Zhu \& Kaplan (1985). At each time-point, $5 \mu \mathrm{g}$ RNA was dot-blotted onto a GeneScreen membrane (New England Nuclear) or a nitrocellulose membrane (Schleicher and Schuell) using a mini-fold dot-blot apparatus (Schleicher and Schuell). Blots were probed either with nick-translated pDC100 (Cook et al., 1989) which carries the $f b c$ operon encoding the cytochrome b/cl complex (Gabellini \& Sebald, 1986), or with recombinant M13 phage derivative T319 containing a portion of the $p u f A$ gene which codes for the $\alpha$ subunit of the LHI antenna complex (Youvan et al., 1984) labelled by primer-extension, or with a $5^{\prime}$ end-labelled 15-mer oligonucleotide complementary to the $p u c B$ gene encoding the LHII $\beta$ subunit of the LHII antenna complex (Zhu \& Hearst, 1986). To account for fluctuations in the amounts of RNA dotted, serial dilutions of each RNA stock were probed with nick-translated pRC1 plasmid which encodes $R$. capsulatus rRNA genes (Yu et al., 1982). After hybridization and autoradiography, dots were quantified by scintillation counting in $5 \mathrm{ml}$ of Opti-Fluor (Packard) in a Packard model 3385 scintillation counter, or by scanning autoradiograms in their linear response range with a Hoeffer GS-300 transmittance-reflectance densitometer. Data for mRNA hybridizations were normalized based on rRNA hybridization using $\mathrm{pRCl}$ as a probe.

\section{Results}

Dark respiratory growth of $R$. capsulatus strains in the presence of DMSO at low-oxygen concentrations

Strain SB1003, which is wild-type for the photosynthetic genes, and its derivative KZR8E12, which lacks BChl (Zsebo \& Hearst, 1984), were grown on a nonfermentable medium in the presence $\left(\mathrm{RCV}^{+}\right)$or absence (RCV) of added DMSO. KZR8E12 carries a $b c h D:: \operatorname{Tn} 5.7$ mutation and is blocked in one of the first two reactions of $\mathrm{BChl}$ biosynthesis starting from protoporphyrin IX (Biel \& Marrs, 1983). Cultures were maintained in the dark throughout the experiment. When cells reached early exponential phase, they were shifted from a $20 \%$ to a $3 \%$ oxygen concentration. This drop in oxygen tension is sufficient to allow induction of photosynthetic genes in the wild-type strain when grown without illumination on unsupplemented RCV medium

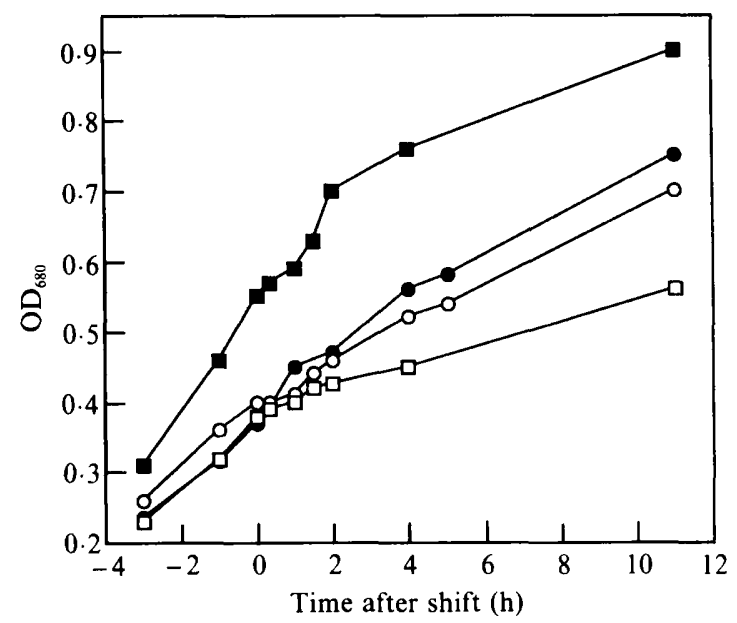

Fig. 1. Growth curves during dark shift from $20 \%$ to $3 \%$ oxygen concentration of $R$. capsulatus strain SB1003 in RCV ( $\mathbf{D})$ and $\mathrm{RCV}^{+}$ $(O)$, and strain KZR8E12 in RCV ( $\square)$ and in $\mathrm{RCV}^{+}(\mathrm{O})$.

(Oelze \& Drews, 1972). We chose a shift to $3 \% \mathrm{O}_{2}$ for our studies because we observed no growth of SB1003 or KZR8E12 cultures when they were shifted to $0 \% \mathrm{O}_{2}$ in the dark unless DMSO was present in the medium, as has been previously reported (Schultz \& Weaver, 1982; Richardson et al., 1988). Growth of the cultures was monitored for $11 \mathrm{~h}$ after the shift from $20 \%$ to $3 \% \mathrm{O}_{2}$. The doubling time in $20 \%$ oxygen was about $4 \mathrm{~h}$ for both SB1003 and KZR8E12, whether the medium was supplemented with DMSO or not (Fig. 1). When oxygen tension dropped to $3 \%$, the cultures resumed growth at a slower rate with only a short adaptive period compared to the 90-120 min lag phase observed when shifting a wild-type Rhodobacter culture to strictly anaerobic photosynthetic growth conditions (Gray, 1967; Cook et al., 1989). The longer lag-phase in the latter experiments can be explained by the more dramatic nature of the shift from respiratory to photosynthetic conditions. After the shift from $20 \%$ to $3 \% \mathrm{O}_{2}$, cultures grew with an average doubling-time of $14 \mathrm{~h}$ for SB 1003 and $18 \mathrm{~h}$ for KZR8E12 in RCV medium (Fig. 1) indicating slow respiratory growth with $3 \% \mathrm{O}_{2}$ in the absence of alternate terminal oxidants. When the medium was supplemented with DMSO, growth subsequent to the $\mathrm{O}_{2}$ step-down resumed with a generation time of $6 \mathrm{~h}$ and $10 \mathrm{~h}$ for strains SB 1003 and KZR8E12, respectively. The generation times were averaged over three experiments and are in accord with published values for growth on supplemented malate medium in a completely anaerobic environment, which range from 7 to $14 \mathrm{~h}$, depending on strain type (Schultz \& Weaver, 1982; Richardson et al., 1988). Cultures of the same strains in $\mathrm{RCV}^{+}$shifted to $0 \%$ oxygen had similar growth rates as when shifted to $3 \%$ oxygen concentration (data not shown). The presence of low levels of oxygen in 


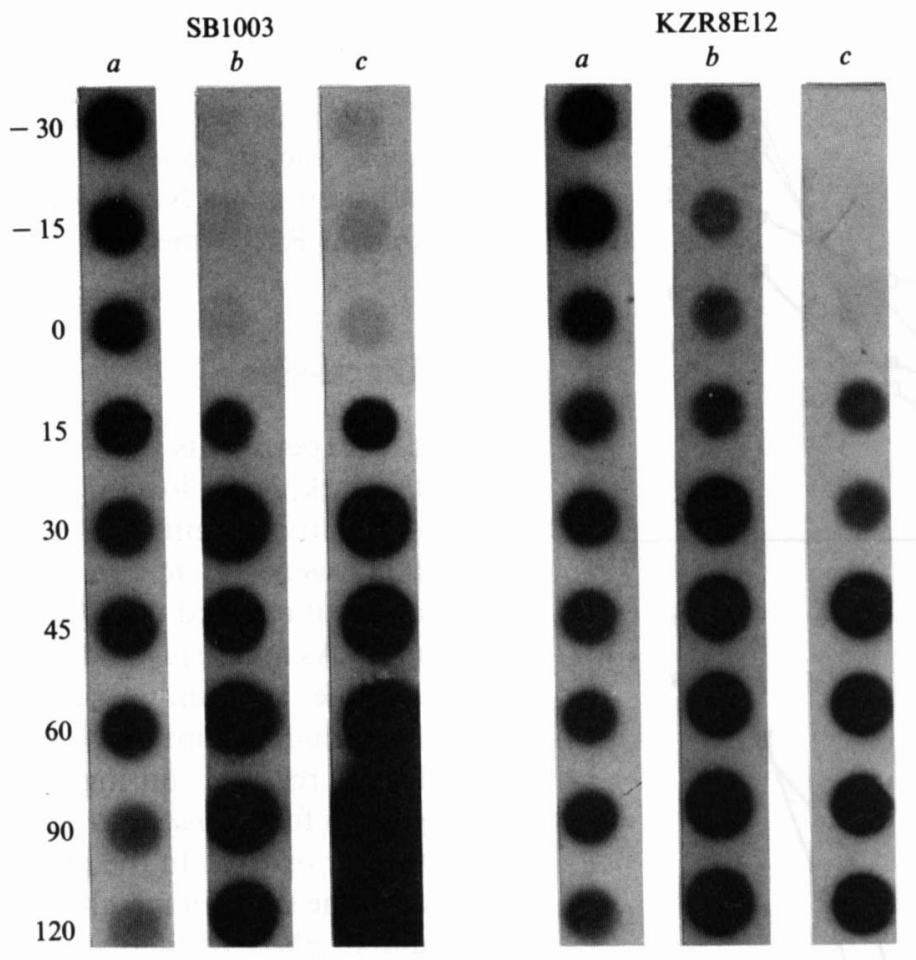

Fig. 2. Dot-blot hybridization of $R$. capsulatus strains SB1003 and KZR8E12 with probes for $f b c(a)$, puf $(b)$ and puc $(c)$ operons. Total RNA was collected at the time indicated ( $\mathrm{min}$ ) following the shift in oxygen tension from $20 \%$ to $3 \%$, and $5 \mu \mathrm{g}$ was dotted for hybridization. Autoradiograms obtained from cultures grown in $\mathrm{RCV}^{+}$and $\mathrm{RCV}$ were similar, and only data corresponding to the shift in $\mathrm{RCV}^{+}$are shown.

the $\mathrm{RCV}^{+}$cultures thus did not grossly disturb the metabolic balance established by the use of the alternative DMSO respiratory pathway.

\section{Expression of fbc mRNA for the cytochrome b/cl complex remains constant}

Amounts of mRNA for the cytochrome b/cl complex encoded by the $f b c$ operon (Gabellini \& Sebald, 1986) have been shown to remain constant throughout shifts from aerobic to anaerobic photosynthetic growth conditions in strain SB1003 (Cook et al., 1989). Since the cytochrome $\mathrm{b} / \mathrm{cl}$ complex is used during both photosynthetic and aerobic growth, but not during growth with the alternative DMSO respiratory pathway (Daldal, 1988), we first examined whether $f b c$ expression was also constitutive during a dark shift in DMSO-supplemented media. Fig. 2 shows that when both the wild-type and the $b c h D$ mutant KZR8E12 strains are shifted from $20 \%$ to $3 \% \mathrm{O}_{2}$ in the presence of added DMSO the amount of $f b c$ mRNA remains constant.

The puf operon induction is similar in the wild-type and a BChl-minus mutant

We next investigated whether expression of other genes necessary for photosynthesis was constitutive or induc- ible during dark respiratory growth $\left(3 \% \mathrm{O}_{2}\right)$ with DMSO, with respect to levels of mRNA found during dark aerobic respiration $\left(20 \% \mathrm{O}_{2}\right)$. Transcript accumulation from the puf operon encoding LHI antenna and $\mathrm{RC}$ structural polypeptides was monitored over a $2 \mathrm{~h}$ period after reducing the oxygen tension. The puf operon both in SB1003 and its bchD derivative KZR8E12 showed transcriptional responses to the lowering of the oxygen tension in both unsupplemented and DMSO supplemented media (Figs 2 and $3 a$ ). The increase in pufA mRNA was 6 to 15 -fold over the basal levels observed before the shift for all four cultures. Amounts of pufA mRNA in strain KZR8E12 were on the average $36 \%$ higher than in the wild-type. However, there was no significant difference in accumulation of pufA mRNA between the wild-type and the BChl-less mutant strain in the conditions used in this study.

puc $m R N A$ induction differs in the wild-type and a BChl-less mutant

We also probed for mRNA from the puc operon, encoding the LHII antenna polypeptides (Youvan \& Ismael, 1985), since the pattern of accumulation of the puc mRNA is different from that of puf mRNA in wildtype strains. Maximal puc mRNA accumulation occurs 


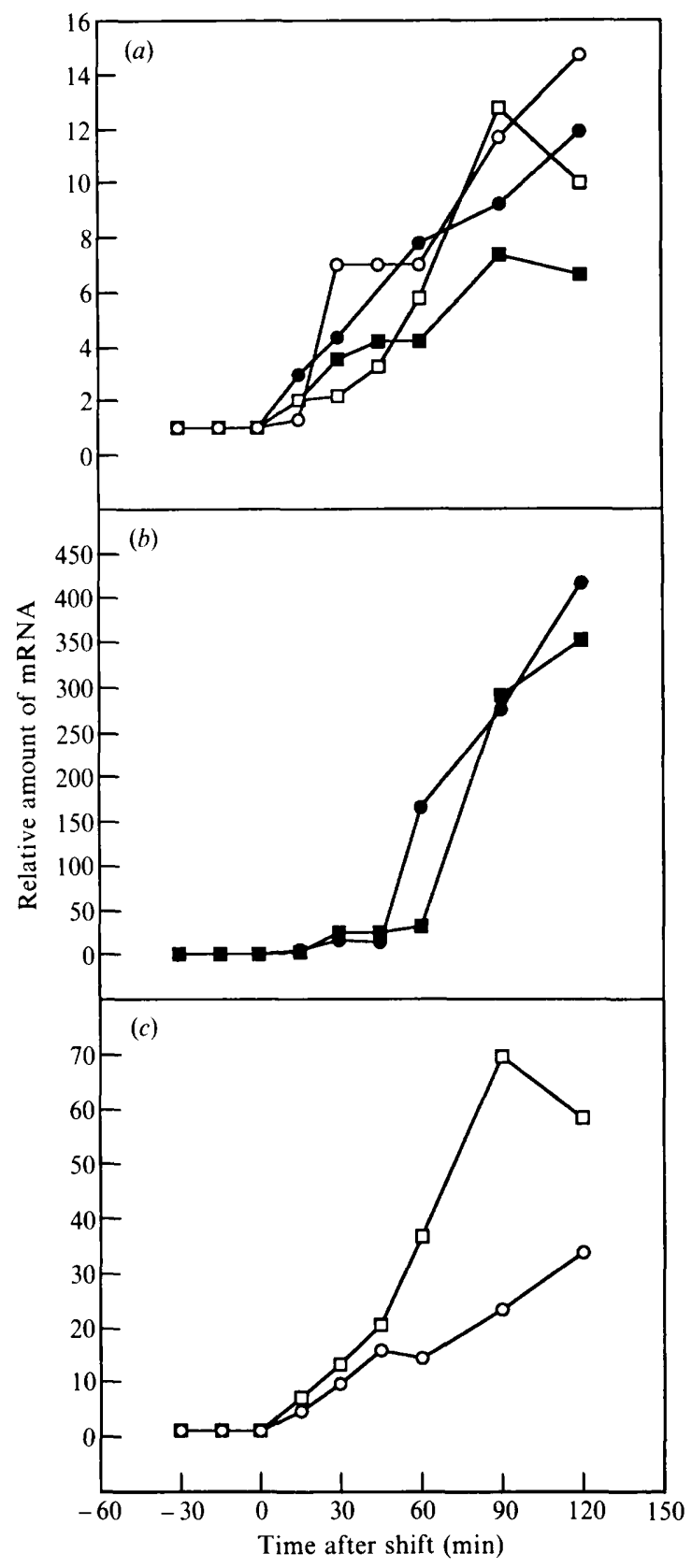

Fig. 3. Time-course of $p u f(a)$ and $p u c$ ( $b$ and $c$ ) mRNA accumulation for dark-shifted cultures of SB1003 (filled symbols) and KZR8E12 (open symbols), respectively, in $\mathrm{RCV}$ and $\mathrm{RCV}^{+}$media. mRNA values are relative to basal levels for each culture. After autoradiography, dots were quantified by scintillation counting.

30 min later than maximal puf mRNA accumulation during development of the photosynthetic membrane (Klug et al., 1985). We observed that transcription in the wild-type strain was induced similarly in both RCV and $\mathrm{RCV}^{+}$media, with mRNA amounts 120 min post-shift up to 400 -fold higher than the pre-shift values. For both cultures, induction of the puc operon was delayed when compared to that of the puf operon (Fig. $3 b$ and $c$ ), in agreement with the results obtained by Klug et al. (1985). Although the magnitude of $p u c$ mRNA accumulation at 120 min post-shift is reduced when compared to wildtype, the BChl-less strain KZR8E12 also showed a substantial mRNA induction of 30-fold in RCV and 70fold in $\mathrm{RCV}^{+}$media.

\section{Discussion}

The experiments we describe in this paper show that in the dark, under low oxygen tension in the presence of an alternative terminal oxidant such as DMSO, photosynthetic genes in $R$. capsulatus are not fully derepressed, and still respond to $\mathrm{O}_{2}$ regulation. The accumulation of mRNAs for the puf and puc operons is similar whether or not the medium is supplemented with DMSO. The magnitude of mRNA accumulation is comparable to levels reached during adaptation to photosynthetic growth for the puf operon, whereas it is much higher for the puc operon. In the presence of DMSO, growth slows after the shift from high to low oxygen concentration, but unlike photosynthetic cultures, no marked lag-time for adaptation is observed. In these growth conditions, bacteria develop a chromatophore membrane gratuitously, but do not need to wait for its completion to resume growth. They rely on an energy-generating mechanism which is already in place, but which is less efficient in generating cell mass when compared to aerobic growth (Fig. 1). The initial controversy as to the role of added oxidants such as DMSO, as either electron sinks to maintain favourable cellular redox potentials (Marrs \& Gest, 1973; Cox et al., 1980; Madigan et al., 1980; Zannoni \& Marrs, 1981) or as participants in an electrogenic pathway (Yen \& Marrs, 1977; Schultz \& Weaver, 1982; McEwan et al., 1983) has only recently been clearly resolved. Rhodobacter capsulatus, like many non-photosynthetic bacteria, has two proton-translocating respiratory pathways. One pathway can function in complete anaerobiosis as well as in microaerophilic conditions, and uses either DMSO, TMAO, nitrate or nitrous oxide as terminal oxidants instead of oxygen (McEwan et al., 1984; Richardson et al., 1988). It has been determined that during anaerobic respiration, electrons pass from the NADH dehydrogenase to the quinone pool, by-passing the cytochrome $\mathrm{b} / \mathrm{cl}$ complex, and proceed to the DMSO/TMAO or the nitrous oxide reductase. This electron transport is coupled to ATP production (Richardson et al., 1986).

The increase in pufA mRNA for the photosynthetic wild-type strain SB1003 was comparable to the 8 to 15 fold range previously reported by several authors (Bauer et al., 1987; Klug et al., 1986; Cook et al., 1989). In the $2 \mathrm{~h}$ induction experiments we describe here, $p u c B$ 
mRNA continued to increase up to about 400 -fold at the end of the time-course, three-fold higher than any puc mRNA increase reported previously. Differences in amounts of puc mRNA between high and low oxygen cultures vary widely in the literature, ranging from 6-fold to 100-fold (Klug et al., 1984; Klug et al., 1985; Zhu \& Hearst, 1986). We attribute these differences to experimental procedures, puc mRNA being much more sensitive than puf mRNA to environmental factors ( $\mathrm{Zhu}$ et al., 1986), and to differences in the bacterial strains. When we shifted a dark, aerobically-grown SB 1003 culture to totally anaerobic conditions, we observed a maximal increase of puc mRNA accumulation of only 20-fold compared to pre-shift levels (data not shown). It thus appears that the maximal inducibility of puc mRNA occurs at oxygen tensions greater than $0 \%$ in spite of the faster degradation rate reported for puc mRNA in cells exposed to fully aerobic conditions (Zhu et al., 1986).

The puf and puc operons in strain KZR8E12, a $b c h D:: \operatorname{Tn} 5.7$ derivative of $\mathrm{SB} 1003$ blocked in one of the first two reactions of $\mathrm{BChl}$ biosynthesis after protoporphyrin IX, show a qualitatively wild-type response at the transcriptional level to a drop in oxygen tension. puf $A$ mRNA induction was similar to that of the wild-type strain. This result is in accord with that of Bauer et al. (1987), who observed oxygen regulation of puf operon expression in $\mathrm{BChl}$ mutants using plasmid-borne lac $Z$ transcriptional gene fusions to monitor promoter activity. In the case of the puc operon, the level of induction was ten-fold lower in the $b c h D$ strain than in the wildtype in RCV, and partially compensated for by the addition of DMSO to the media. This differential regulation of the puf and puc operons cannot be attributed to the crtD carotenoid biosynthesis pointmutation also carried by KZR8E12, since this latter mutation does not affect expression of genes encoding the LHI and LHII polypeptides (Armstrong, 1989). A differential regulation between puf and puc mRNA was also seen by Klug et al. (1986) for strain YS, a $b c h C$ mutant. In their case, however, these authors observed no induction of the puc operon and only a slight induction of puf mRNA. We conclude that the requirements for the normal accumulation of mRNA for the structural components of the LHI and LHII antenna complexes are different. Neither mature Bchl nor a precursor beyond Mg-protoporphyrin IX monomethyl ester is required for induction of mRNA for the LHI complex. In contrast, while we observe a 30 to 70 -fold increase of puc mRNA in the $b c h D$ mutant KZR8E12 $2 \mathrm{~h}$ after lowering the oxygen tension, the full 400 -fold accumulation of this mRNA with wild-type kinetics is dependent on the presence of a compound participating in the biosynthesis of $\mathrm{Mg}$-porphyrins. Whether the effect is exerted on overall mRNA levels, or merely affects the rate of
mRNA accumulation, is outside the scope of our shift experiments.

Growth shifts were performed in the dark, using conditions where cultures of both the wild-type and the BChl mutant strains could continue to grow after lowering the oxygen tension. Although both strains grew at different rates subsequent to the shift to $3 \%$ oxygen in $\mathrm{RCV}$ and $\mathrm{RCV}^{+}$media, transcriptional control of the puf and puc operons was retained, proving that dark respiration with DMSO is compatible with the regulation of photosynthetic gene expression by oxygen tension. Gene regulation of the puf and puc operons is therefore independent of the ATP-producing pathway, be it photosynthesis, or aerobic respiration at oxygen tensions as low as $3 \%$ with or without an accessory terminal oxidant in the form of DMSO. Both TMAO and DMSO are naturally occurring compounds considered to be intermediates in the global sulphur cycle (Lovelock $e t$ $a l ., 1972$ ). They are generated mainly as by-products of phytoplankton activity and are present in ecosystems which host Rhodospirillaceae. Recently a DMSO reductase has been purified and characterized from $R$. capsulatus (McEwan et al., 1985, 1989). Mixed forms of ATP-generation are therefore compatible with normal photosynthetic gene regulation, and can indeed be postulated to take place in vivo in low light environments, where energy supply by light-driven proton translocation is limited.

We thank Dr G. Drews for kindly providing plasmid pRC1, Dr N. Gabellini for pRSF1, D. Cook for pDC100, and Dr Y.-S. Zhu for advice on RNA isolation techniques. This work was supported by the Director, Office of Energy Research, Office of Basic Energy Science, Division of Biological Energy Research, US Department of Energy under Contract No. DE-AC03-76SF00098.

\section{References}

ARMSTRONG, G. A. (1989). A molecular genetic analysis of carotenoid biosynthesis and the effects of carotenoid mutations on other photosynthetic genes in Rhodobacter capsulatus. PhD thesis, University of California, Berkeley, USA.

Bauer, C. E., Eleuterio, M., Young, D. A. \& Marrs, B. L. (1987). Analysis of transcription through the Rhodobacter capsulatus puf operon using a transcriptional fusion of pufM to the $E$. coli $L a c Z$ gene. In Progress in Photosynthesis Research, pp. 699-705. Edited by J. Biggins. Dordrecht, The Netherlands: Nijhoff.

BIEL, A. J. \& MARRS, B. L. (1983). Transcriptional regulation of several genes for bacteriochlorophyll biosynthesis in Rhodopseudomonas capsulata in response to oxygen. Journal of Bacteriology 156, 686-694.

COOK, D. N., ARMSTRong, G. A. \& Hearst, J. E. (1989). Induction of anaerobic gene expression in Rhodobacter capsulatus is not accompanied by a local change in chromosomal supercoiling as measured by a novel assay. Journal of Bacteriology 171, 4836-4843.

Cox, J. C., Madigan, M., Favinger, J. F. \& Gest, H. (1980). Redox mechanisms in 'oxidant-dependent' hexose fermentation by Rhodopseudomonas capsulatus. Archives of Biochemistry and Biophysics 204, 10-17.

DaLDAL, F. (1988). Cytochrome $c 2$ independent respiratory growth of Rhodobacter capsulatus. Journal of Bacteriology 170, 2388-2391. 
Gabellini, N. \& Sebald, W. (1986). Nucleotide sequence and transcription of the $f b c$ operon from Rhodopseudomonas sphaeroides. European Journal of Biochemistry 154, 569-579.

GraY, E. D. (1967). Studies on the adaptive formation of photosynthetic structures in Rhodopseudomonas sphaeroides. I. Synthesis of macromolecules. Biochimica et Biophysica Acta 138, 550-563.

Klug, G., Kaufman, N. \& Drews, G. (1984). The expression of genes encoding proteins of B800-850 antenna-pigment complex and ribosomal RNA of Rhodopseudomonas capsulata. FEBS Letters 177, $61-65$.

Klug, G., Kaufman, N. \& Drews, G. (1985). Gene expression of pigment-binding proteins of the bacterial photosynthetic apparatus: transcription and assembly in the membrane of Rhodopseudomonas capsulata. Proceedings of the National Academy of Sciences of the United States of America 82, 6485-6489.

Klug, G., Liebantz, R. \& Drews, G. (1986). The influence of bacteriochlorophyll biosynthesis on formation of pigment-binding proteins and assembly of pigment protein complexes in Rhodopseudomonas capsulata. Archives of Microbiology 146, 284-291.

Lovelock, J. E., MaGgs, R. J. \& RASMUSSEN, R. A. (1972). Atmospheric dimethylsulphide and the natural sulphur cycle Nature, London 237, 452-453.

McEwan, A. G., Ferguson, S. J. \& Jackson, J. B. (1983). Electron flow to dimethyl- $N$-oxide generates a membrane potential in Rhodopseudomonas capsulatus. Archives of Microbiology 136, 300-305.

MCEwAN, A. G., FERGUSON, S. J. \& JACKSON, J. B. (1984). Rationalization of properties of nitrate reductases in Rhodopseudomonas capsulatus. Archives of Microbiology 137, 344-349.

McEwan, A. G., Wetzstein, H. G., Ferguson, S. J. \& Jackson, J. B (1985). Periplasmic location of the terminal reductase in trimethylamine $\mathrm{N}$-oxide and dimethylsulphoxide respiration in the photosynthetic bacterium Rhodopseudomonas capsulatus. Biochimica et Biophysica Acta 806, 410-417.

McEwen, A., Richardson, D. J., Hudig, H., Ferguson, S. \& JACKSON, J. B. (1989). Identification of cytochromes involved in electron-transport to trimethylamine $N$-oxide/dimethylsulphoxide reductase in Rhodobacter capsulatus. Biochemica et Biophysica Acta 973, 308-314.

Madigan, M., Cox, J. C. \& Gest, H. (1980). Physiology of dark fermentative growth of Rhodopseudomonas capsulata. Journal of Bacteriology 142, 908-915.

MarRS, B. \& GeST, H. (1973). Genetic mutations affecting electron transport system of the photosynthetic bacterium Rhodopseudomonas capsulata. Journal of Bacteriology 114, 1045-1051.

MARRS, B. (1981). Mobilization of the genes for photosynthesis from Rhodopseudomonas capsulata by a promiscuous plasmid. Journal of Bacteriology 146, 1003-1012.

OELZE, J. \& DREwS, G. (1972). Membranes of photosynthetic bacteria. Biochimica et Biophysica Acta 265, 209-239.

Richardson, D. J., Kelly, D. J., Jackson, J. B., Ferguson, S. J. \& ALEF, K. (1986). Inhibitory effects of myxothiazol and 2-n-heptyl-4- hydroxyquinone- $N$-oxide on the auxiliary electron transport pathways of Rhodobacter capsulatus. Archives of Microbiology 146, 159-165.

Richardson, D. J., King, G. F., Kelly, D. J., McEwan, A. G., Ferguson, S. J. \& JACKSON, J. B. (1988). The role of auxiliary oxidants in maintaining redox balance during phototrophic growth of Rhodobacter capsulatus on propionate or butyrate. Archives of Microbiology 150, 131-137.

SchulTZ, J. E. \& WeAver, P. F. (1982). Fermentation and anaerobic respiration by Rhodospirillum rubrum and Rhodopseudomonas capsulata. Journal of Bacteriology 149, 181-190.

WeAver, P. F., Wall, J. D. \& GeST, H. (1975). Characterization of Rhodopseudomonas capsulata. Archives of Microbiology 105, 207216.

YEN, H.-C. \& MARRS, B. (1977). Growth of Rhodopseudomonas capsulata under anaerobic dark conditions with dimethyl sulfoxide. Archives of Biochemistry and Biophysics 181, 411-418.

Youvan, D. C., Bylina, E. J., Alberti, M., Begusch, H. \& Hearst, J. E. (1984). Nucleotide and deduced polypeptide sequences of the photosynthetic reaction-center, B870 antenna and flanking polypeptides from $R$. capsulata. Cell 37, 949-957.

Youvan, D. C. \& IsmaIL, S. (1985). Light-harvesting II (B800-B850) complex structural genes from Rhodopseudomonas capsulata. Proceedings of the National Academy of Sciences of the United States of America 82, 58-62.

YU, P. L., HoHN, B., FALK, H. \& Drews, G. (1982). Molecular cloning of the ribosomal RNA genes of the photosynthetic bacterium Rhodopseudomonas capsulata. Molecular and General Genetics 188 , 392-398

ZANNONI, D. \& MARRS, B. L. (1981). Redox chain and energy transduction in chromatophores from Rhodopseudomonas capsulata cells grown anaerobically in the dark on glucose and dimethyl sulfoxide. Biochimica et Biophysica Acta 637, 96-106.

ZHU, Y.-S. \& KAPLAN, S. (1985). Effects of light, oxygen, and substrates on steady-state levels of mRNA coding for ribulose-1,5bisphosphate carboxylase and light-harvesting and reaction center polypeptides in Rhodopseudomonas sphaeroides. Journal of Bacteriology 162, 925-932.

Zhu, Y.-S., CoOK, D. N., Leach, F., Armstrong, G. A., Alberti, M. \& Hearst, J. E. (1986). Oxygen-regulated mRNAs for lightharvesting, bacteriochlorophyll and carotenoid biosynthesis in Rhodobacter capsulatus during the shift from anaerobic to aerobic growth. Journal of Bacteriology 168, 1180-1188.

ZhU, Y.-S. \& HearsT, J. E. (1986). Regulation of expression of genes for light-harvesting antenna proteins $\mathrm{LH}-\mathrm{I}$ and $\mathrm{LH}-\mathrm{II}$; reaction center polypeptides RC-L, RC-M and $\mathrm{RC}-\mathrm{H}$; and enzymes of bacteriochlorophyll and carotenoid biosynthesis in Rhodobacter capsulatus by light and oxygen. Proceedings of the National Academy of Sciences of the United States of America 83, 7613-7617,

Zsebo, K. M. \& HeARST, J. E. (1984). Genetic-physical mapping of a photosynthetic gene cluster form $R$. capsulata. Cell 37, 937-9476. 